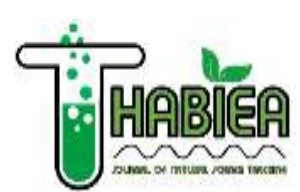

Thabiea: Journal of Natural Science Teaching

Program Studi Tadris Ilmu Pengetahuan Alam

Institut Agama Islam Negeri Kudus

http://journal.stainkudus.ac.id/index.php/Thabiea

p-issn: 2580-8974, e-issn: 2655-898x

\title{
Pembelajaran Ilmu Pengetahuan Alam Berbasis EMC (Education Mini Club) sebagai Solusi Menghadapi Tantangan Pendidikan di Era Revolusi Industri 4.0
}

\author{
Ayik Wulandari ${ }^{a}{ }^{*}$, Putri Handayani ${ }^{\text {b, } 2}$, Dody Rahayu Prasetyo ${ }^{c, 3}$ \\ a,b,c Institut Agama Islam Negeri (IAIN) Kudus \\ ${ }^{1}$ ayikwulan06569@gmail.com*; putriana240@gmail.com; dodyslash89@gmail.com
}

\begin{tabular}{ll}
\hline Informasi artikel & ABSTRAK \\
\hline Kata kunci: & Artikel ini bertujuan untuk mengetahui peningkatan pembelajaran ilmu \\
Pembelajaran IPA, & pengetahuan alam (IPA) dengan menggunakan metode Education Mini \\
EMC, & Club (EMC) sebagai solusi dalam menghadapi tantangan pendidikan \\
Revolusi Industri 4.0 & diera revolusi 4.0 penelitian ini di lakukan karena adanya proses \\
& pembelajaran yang kurang sesuai dengan keadaan siswa yang tidak \\
& suka dengan metode pembelajaran yang monoton. Metode yang \\
& digunakan dalam penelitian ini yaitu dengan metode observasi lapangan \\
& yang artinya pengamatan secara langsung dilapangan. Pelaksanaan \\
& observasi yang dilakukan di MTs Nu Ibtidaul Falah. Analisis data \\
& menunjukkan adanya peningkatan hasil belajar dengan menggunakan \\
& metode EMC. Data tersebut didapat dari hasil nilai pre-test sebelum di \\
& terapkannya medode EMC dibandingkan dengan nilai setelah \\
& dterapkannya metode EMC. Hasil nilai yang diperoleh lebih bagus \\
& setelah di terapkannya metode EMC. Sebelum di terapkannya ada \\
& beberapa siswa yang belum mncapai kriteria ketuntasan minimum \\
& (KKM) yang di tetapkan pihak sekolah setelah di terapakan metode \\
& EMC ini siswa semua telah mencapai KKM.
\end{tabular}

\begin{tabular}{ll}
\hline Key word: & ABSTRACT \\
Science learning, & Education Mini Club (EMC)-Based Science Learning as a Solution \\
EMC, & to Facing Educational Challenges in the Era of Industrial \\
Industrial Revolution 4.0. & Revolution 4.0 This article aims to improve the learning of natural \\
& sains by using the Education Mini Club (EMC) education method as a \\
& solution to face the challenges of education in the revolutionary era 4.0. \\
& This research was conducted because of the learning proses that wasn't \\
& in accordance with whit the condition of students who didn't like the \\
& monotonous learning methods. The method used in this study is the field \\
observation method which means direct observation in the field. & Implementation of observation carried out in MTs NU Ibtidaul Falah \\
& who got data analysis of an increase in learning outcomes using the \\
& method an Education Mini Club. The data is obtained from the results \\
of the pre-test value or before the implementation of mini club \\
education method compared to the value after the implementation of \\
this mini club education method results obtained better value after \\
being applied to the mini club education.
\end{tabular}

Copyright (C) 2019 Institut Agama Islam Negeri Kudus. All Right Reserved 


\section{Pendahuluan}

Revolusi industri dimulai pada abad 18 yang membawa pengaruh terhadap kemajuan suatu bangsa termasuk di Indonesia. Untuk antisipasi revolusi industri 4.0 pemerintah Indonesia membuat roadmap diantaranya meliputi kegiatan, dibidang SDM, inovasi dan teknologi. Dalam industri 4.0 manusia harus memiliki kemampuan untuk memprediksi masa depan yang berubah sangat cepat. Tantangan pada era revolusi industri 4.0 diantaranya yaitu 1) Tantangan ekonomi, 2) Tantangan sosial, 3) Tantangan teknis, 4) Tantangan lingkungan, 5) Tantangan politik dan aturan.

\section{Menurut Kemendikbud}

Pembelajaran merupakan proses interaksi antar peserta didik dengan pendidik dan sumber belajar pada suatu lingkungan belajar. Pendidikan 4.0 adalah fenomena yang merespon kebutuhan munculnya revolusi industri keempat (4 IR) dimana manusia dan mesin diselaraskan untuk mendapatkan solusi, memecahkan masalah, dan tentu saja menemukan kemungkinan inovasi baru. Pembelajaran di era revolusi industri 4.0 diharapkan untuk mendapatkan generasi yang unggul, inovatif, menghasilkan produk dan memberikan penguatan pada ekonomi kreatif kerakyatan. Pendidikan pada era industri 4.0 perlu dipandang sebagai pengembangan kompetensi abad ke 21 yang terdiri dari kompetensi berfikir, bertindak, dan keterampilan beradaptasi. Berbagai upaya telah dilakukan termasuk pembelajaran berbasis penyelidikan untuk meningkatkan kompetensi siswa di abad ke-21 termasuk model inquiry baik open inquiry maupun guided inquiry (Fikri, Ismah, \& Paidi, 2018).
Dalam proses pembelajaran IPA berkaitan erat dengan teknologi revolusi industri 4.0, karena kajian IPA meliputi aspek produk, proses, sikap ilmiah dan aplikasi. Pembelajaran sains di mulai dari tingkat madrasah ibtidaiyyah, dituntut untuk mengikuti perkembangan teknologi. Meskipun demikian, pembelajaran juga tidak dapat dipisahkan dari karakter Islam sebagai karakteristik madrasah. Pemberlajaran IPA biasnya melibatkan siswa untuk praktik. Hal ini dapat menumbuhkan berbagai macam karakter dalam diri siswa (Fawaida, 2019). IPA sebagai produk berupa tubuh pengetahuan yang terdiri dari konsep, prinsip, hukum dan teori. Proses IPA terdiri dari keterampilan-keterampilan proses untuk mendapatkan dan mengembangkan pembelajaran IPA. Dalam pembelajaran IPA memiliki metode diantaranya 1) metode ceramah, 2) metode demonstrasi, 3) metode diskusi, 4) metode simulasi, 5) metode tugas dan resitasi, dan 6) metode tanya jawab.

Pembelajaran IPA lebih tepat menggunakan metode diskusi yang bersifat Mini Club. Secara umum metode ini merupakan suatu metode dalam diskusi yang membahas tentang suatu topik dengan cara bertukar pikiran antara 2 orang atau lebih dalam kelompok-kelompok kecil yang direncanakan untuk mencapai tujuan tertentu. Roestiyah N.K (1991:5) berpendapat bahwa pembelajaran dengan menggunakan metode EMC adalah salah satu Teknik belajar mengajar yang dilakukan oleh seorang guru disekolah, dimana proses interaksi antar dua atau lebih individu yang terlibat, saling tukar menukar pengalaman, informasi, memecahkan masalah, dapat terjadi juga semuanya aktif 
dan tidak ada yang pasif sebagai pendengar saja.

$\begin{array}{ccc}\text { Namun, } & \text { sering kali } & \text { dalam } \\ \text { pembelajaran } & \text { dijumpai } & \text { adanya }\end{array}$ kecenderungan siswa yang tidak mau bertanya kepada guru meskipun sebenarnya mereka belum mengerti tentang materi yang disampaikan guru. Masalah seperti inilah yang juga terjadi di sekolah Madrasah Tsnawiyah (MTs) NU Ibtidaul Falah Samirejo Dawe Kabupaten Kudus. Sehingga dipandang perlu diadakan penelitian tindakan dengan menerapkan metode Education Mini Club (EMC) pada pembelajaran IPA. Pelaksanaan EMC ini diharapkan dapat membantu meningkatkan hasil dalam pembelajaran IPA di kelas VIII MTs NU Ibtidaul Falah Samirejo Dawe kabupaten Kudus.

Pembelajaran IPA diarahkan untuk berkelompok dan berbuat sehingga dapat membantu peserta didik untuk memperoleh pemahaman yang lebih mendalam tentang alam sekitar. Seorang guru dalam pembelajaran IPA sering kali hanya berpatokan kepada buku saja yaitu hanya menjelaskan, mencatat, dan latihan. Sehingga yang dirasakan oleh siswa terlalu monoton dan bahkan membosankan. Karena dalam pembelajaran hanya didominasi oleh guru, sehingga siswa kurang berinteraksi dan bekerja sama dalam memecahkan masalah, siswa tampak bosan dalam pelaksanaan proses kegiatan pembelajaran. Penyebab lain adalah kurangnya inovasi guru terhadap model, strategi, dan metode pengajaran dalam penyampaian materi.

\section{Metode penelitian}

Penelitian ini termasuk dalam penelitian kuantitatif dan bersifat deskriptif.
Penelitian ini dimaksudkan untuk menguji hipotesis atau menjawab permasalahan yang menyangkut keadaan pada waktu itu, yang sedang berjalan atau situasi yang ada pada saat ini. Model deskriptif merupakan suatu prosedur pemecahan masalah yang diselidiki dengan menggambarkan keadaan subjek atau objek penelitian (seseorang, lembaga, masyarakat,dan lain-lain) berdasarkan fakta-fakta yang tampak, atau sebagaimana adanya. Model deskriptif yang digunakan dalam penelitian ini adalah deskriptif survei, yaitu penelitian yang dilakukan pada populasi besar ataupun kecil. Pengukuran data pokok yang dilakukan disekolah MTs di kudus kelas VIII pada bulan April 2019 ini menggunakan kuesioner atau berupa angket.

Adapun populasi dalam penelitian ini adalah semua siswa MTs kelas Vlll. Sedangkan Teknik pengambilan sample ini dilakukan secara perwakilan dan sesuai dengan perbandingan frekuensi didalam populasi secara keseluruhan. Objek dari penelitian ini adalah metode pembelajaran IPA yang berbasis EMC dan sebagai subjeknya adalah siswa-siswi dan guru IPA.

Dalam penelitian ini menggunakan 3 teknik pengumpulan data yaitu observasi atau pengamatan langsung yang dilakukan di MTS di kudus, selanjutnya teknik wawancara, dalam hal ini mengadakan komunikasi secara langsung dengan pihak guru IPA untuk mendapatkan data objektif mengenai masalah yang menjadi objek penelitian, kemudian Teknik kuesioner atau angket berisi rangkaian pertanyaan mengenai suatu masalah dalam bidang Mini Club, yang nantinya angket tersebut akan disebarkan kepada siswa-siswi. 
Teknik pengumpulan data pada penelitian ini dilakukan setelah semua data selesai dikumpulkan dengan lengkap, dan tahap selanjutnya adalah tahap pengolahan data yang dilakukan dengan berbagai cara yaitu editing, skoring, dan tabulating.

\section{Hasil dan pembahasan}

Melalui penggunaaan metode Mini Club, siswa juga mendapat kesempatan untuk latihan keterampilan berkomunikasi dan keterampilan untuk mengembangkan strategi berpikir dalam memecahkan masalah. Dari beberapa ahli juga berpendapat mengenai tujuan dari metode Mini Club salah satunya yaitu Soli Abimanyu, dkk (2009: 6-17) mengemukakan bahwa tujuan diadakannya Mini Club adalah sebagai berikut: a. Memecahkan materi pembelajaran yang berupa masalah problematic yang sukar dilakukan oleh siswa secara individu. b. Mengembangkan keberanian siswa dalam mengemukakan pendapat. c. mengembangkan sikap toleran terhadap pendapat yang berbeda. dan. melatih siswa mengembangkan sikap demokratis, keterampilan, berkomunikasi, mengeluarkan pendapat, menafsirkan, dan menyampaikan pendapat. Dalam penelitian ini mengenai pembelajaran IPA menggunakan metode Education Mini Club (EMC), terlebih dahulu pada awal penelitian diberikan pretest yaitu dengan menggerjakan soal yang telah siapkan berdasarkan materi pada pembelajaran IPA dikelas Vlll D MTs Nu Ibtidaul Falah. Dari hasil pretest ada beberapa siswa yang nilainya rendah hal ini disebabkan kurangnya penguasaan materi yang menjadi soal pretest saat itu.

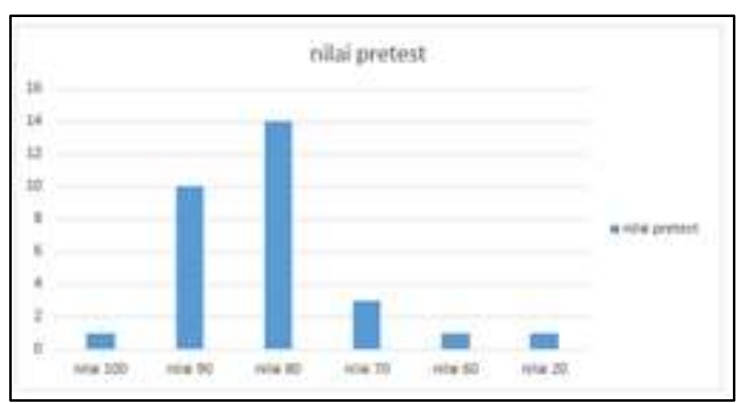

Gambar 1. Nilai pretest siswa kelas VIII MTs Ibtidaul Falah

Berdasarkan Gambar 1 data penelitian dapat diketahui bahwa hasil hitung rata-rata nilai yang diperoleh siswa masih dibawah Kriteria Ketuntasan Minimal (KKM) dengan jumlah siswa sebanyak 5 orang siswa dari 30 siswa. Dari ke 5 siswa tersebut masih mengalami kesulitan dalam menyelesaikan soal-soal pretest sehingga belum mampu mencapai kriteria ketuntasan minimal. Tetapi secara menyeluruh soalsoal pretest yang diberikan berhasil dijawab oleh siswa sebanyak 25 orang siswa dari 30 siswa nilai yang mereka peroleh sudah mencapai ketuntasan.

Dari hasil pretest dapat dilihat bahwa perlu adanya penelitian tindakan kelas dengan menggunakan metode Education Mini Club (EMC) di kelas Vlll D MTs Nu Ibtidaul Falah sebagai upaya untuk meningkatkan hasil belajar siswa pada pembelajaran IPA. Langkah-langkah pada kegiatan inti pelaksanaan Metode EMC ini yaitu, guru mempersiapkan soal mengenai pembelajaran IPA yang kemudian siswa dibagi menjadi 5 kelompok dalam tiap kelompok terdiri dari 6 orang. Setelah itu, siswa berkelompok membentuk Mini Club untuk menyelesaikan soal yang telah diberikan. Setelah diskusi selasai siswa diharuskan mempresentasikan hasil diskusi kelompok yang telah dilakukan dengan tujuan untuk mengetahui jawaban antar kelompok yang membutuhkan ketelitian didalam mengerjakan soal. 


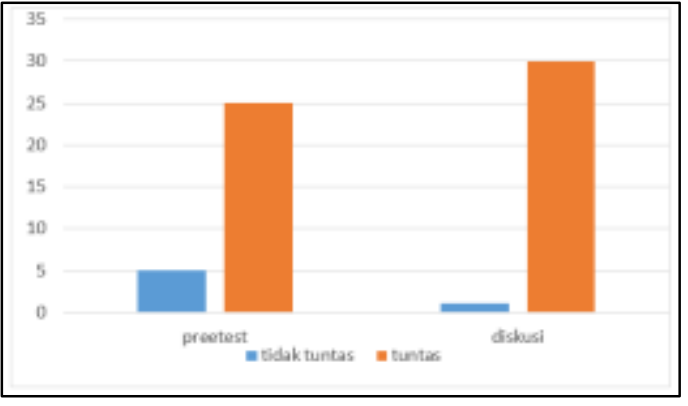

Gambar 2. Nilai pencapaian ketentuan ketuntasan minimum (KKM) kelas VII MTs Ibtidaul Falah

Berdasarkan Gambar 2 hasil penelitian yang telah dilakukan tampak jelas adanya perbandingan dari data tersebut. Ketika siswa diminta untuk mengerjakan soal pretest secara individu masih didapati beberapa anak yang nilainya kurang, sementara itu di sisi lain ketika siswa diminta untuk mengerjakan soal dengan menggunakan metode Education Mini Club. Mereka bisa leluasa aktif di dalam menyampaikan pendapat secara berkelompok dan siswa juga lebih leluasa menggungkapkan permasalahannya kepada sesama kelompok. Dalam hal ini gagasan atau ide pokok dari siswa lain itu sangat berpengaruh sehingga dapat membantu siswa yang nilainya rendah pada saat pretest.

Dari hasil penelitian yang telah dilakukan pada saat diskusi telah berlangsung dalam pembelajaran IPA menggunakan Metode EMC dapat diamati bahwa masih ada beberapa kekurangan di dalam metode ini diantaranya adalah: 1 . Kurang teliti dalam memahami soal yang dikerjakan. 2. Kurang memperhatikan jawaban dari kelompok lain saat presentasi berlangsung. Sehingga hal ini berakibat pada tidak optimalnya diskusi ketika pembelajaran berlangsung.

Abimanyu (2009 : 6-12), berpendapat bahwa ada beberapa cara untuk mengatasi kelemahan dalam metode EMC ini antara lain: (a) Setiap siswa dalam diskusi Mini Club harus memahami masalah yang akan didiskusikan, untuk itu sebagai guru harus terlebih dahulu menjelaskan masalah yang akan dibahas agar siswa dapat memahami dan bisa mengerjakan dengan teliti. (b) Guru harus menempatkan posisi sebagai pemimpin diskusi dalam Mini Club agar dapat mengatur jalannya proses pembelajaran sampai pada proses presentasi sehingga pembelajaran dapat berlangsung dengan tertib dan efektif.

\section{Simpulan}

Dari analisis data dan dengan argument dari beberapa ahli dapat ditarik kesimpulan banwa pengembangan pembelajaran IPA dengan menggunakan metode Education Mini Club (EMC) dapat meningkatkan hasil belajar siswa metode ini juga sudah banyak digunakan oleh beberapa ahli dan setelah penerapan metode ini hasil belajar siswa mengalami peningkatan. Hal tersebut dapat dilihat dari hasil belajar siswa sebelum diterapkannya metode EMC ada beberapa yang belum memenuhi KKM dan setelah diterapkan metode EMC semua siswa telah mencapai KKM.

Dari metode pembelajaran yang telah diterapkan dapat memenuhi harapan terwujudnya SDGs di era industri 4.0 dimana harapan tersebut mampu untuk mendapatkan generasi kreativitas yang unggul, inovatif, menghasilkan produk dan memberikan penguatan pada ekonomi kreatif kerakyatan.

\section{Referensi}

Anisa Nurul, Naelan Simbolon, (2018). Pengmbangan Media Pembelajaran Interaktif IPA Berbasis Model Pembelajaran Guided Inquiry pada Materi Gaya di Kelas IV SD Negri 101776 Sampali. Jurnal Pendidikan (8) Hal. 218-220

B. Suryosubroto, (1997). Proses Belajar Mengajar di Sekolah. Jakarta: PT Rineka Cipta

David Hopkins (2011). Panduan Guru Penelitian Tindakan Kelas. Yogyakarta: Pustaka Pelajar 
Departemen Pendidikan Nasional. (2003). Strategi Pembelajaran. Jakarta: Pusat Pengembangan dan Pemberdayaan Pendidik dan Tenaga Kependidikan

Fawaida, U. (2019). Penguatan Pendidikan Karakter melalui Praktikum IPA di Sekolah Dasar. Prosiding Seminar Nasional Nasional Pendidikan 2019, Universitas Muria Kudus, 176-180.

Fikri, A.A., Ismah, V. \& Paidi, P. (2018). Pengembangan Perangkat Pembelajaran Model Guided Inquiry Untuk Meningkatkan Creative Thinking Siswa. Thabiea: Journal of Natural Science Teaching, 1, (1), Hal 1-8.

Haqiqi, A. K. \& Albar, W. F. Islamic Character in Science Learning for Madrasah Ibtidaiyah Students in the 4.0 Industrial Revolution Era. Proceeding International Conference on Science and Engineering, (2), Hal. 237-240
Kemenristekdikti. (2018). Kebijakan Kemenristekdikti Menghadapi Globalisasi Pendidikan \& Revolusi Industri 4.0 (Press release)

Roestiyah N.K, (1991). Strategi Belajar Mengajar. Jakarta: Rineka Cipta

Soli Abimanyu, dkk. (2009). Strategi Pembelajaran. Jakarta: Dirjendikti Depdiknas

Thaem Albinous, (2012). Metode Diskusi dalam Pembelajaran Struktur Tumbuhan di Kelas IV Sekolah Dasar Negri 10 Sungai Melayu Raya Ketapang. Jurnal Pendidikan. Universitas Tanjung Pura Pontianak. 